\title{
Determining the vehicles routes by considering its different types and capacity (heterogeneous) to minimize the total distribution cost
}

\author{
Nurhidayat and Annie Purwani* \\ Industrial Engineering University of Ahmad Dahlan, J1. Dr. SoepomoJanturan Yogyakarta Indonesia
}

\begin{abstract}
Packaged sugar is one of the products in sugar cane manufacture, PT Madubaru Yogyakarta. Currently, the company deals with a high distribution cost because there is no plan to determine the vehicle route, vehicle type, and capacity for distributing the product. In this research, the optimum route of the distributing vehicles is developed. The company has three different types and capacity of vehicles: L300, HD, and PS. A problem in determining the distribution route here is called as Vehicle Routing Problem (VRP). The basic form of classic VRP says that all vehicles owned by a company have the same capacity (homogenous), meanwhile not all companies have the vehicles with same capacity. The heterogeneous variant is used to minimize the fixed cost of vehicles and distribution variant cost using Sequential Insertion Algorithm. This research has three purposes; are minimizing the number of vehicles used (NV), Total time of Completion tour (TCT) and Distribution Total Cost (TCD). The results based on a test calculation of a shipment date (August 19, 2016) of the company show three alternative solutions to distribute the packaged sugar to 12 consumers. The third alternative solution is the optimal solution and chosen as the decision result of the packaged sugar shipment. Based on the calculation results, it is needed 2 vehicles type HD with capacity $7,000 \mathrm{~kg}$ and type PS with capacity $3,500 \mathrm{~kg}$, with total time of completion tour (TCT) is 828.49 minutes or 13.81 hours, and distribution total cost is IDR. 959,011.
\end{abstract}

\section{Introduction}

PT. Madubaru Yogyakarta is a sugar cane manufacture which has packaged sugar as the final product. $P T$. Madubaru does not have yet optimal configuration of distribution line in distributing the products to retails. Lack of delivery products planning along with the selection of vehicles routes, vehicles capacity, to the vehicles schedules affects improperly configured distribution channels which leads to the high transportation cost. The selection of unorganized vehicle routes leads to a longer vehicle route with longer distance. Therefore, the product distribution requires effective and efficient distribution strategy and planning.

Researches on the distribution of packaged sugar at PT. Madubaru had previously conducted by Ikhsan (2013) which discusses about optimizing the products distribution using saving matrix method, considers that all vehicles have same capacity (homogeneous), with optimizing indicator is the shortest distance. The next study is from Azizah (2015) who compared the saving matrix and general assignment method by considering the same parameters as Ikhsan used. The saving matrix and general assignment methods are part of the heuristic algorithm used to minimize the distance and cost by considering the constraints. In fact, PT. Madubaru has different types and capacity of vehicles so that the method is less effective to optimize the distribution cost of the company.

The problem of determining the distribution route is often known as the Vehicle Routing Problem which refers to a problem where there are several routes must be passed by a number of vehicles that depart from a depot to some destinations that have been determined and ends at the same depot (Hasanah, 2013). To decrease the transportation costs and also improve the services to the customer, it is necessary to find the best path or route, which can minimize the distance and time. Problems that aim to create an optimal route, for a group of vehicles, in order to serve a number of consumers, referred to as Vehicle Routing Problems (Hermansyah, 2011). The basic form of VRP is to assume that all vehicles owned have the same capacity (homogeneous) (Arvianto, 2014). In fact, not all companies have vehicles in the same capacity, either big or small companies. Therefore, the old VRP settlement is difficult to implement to solve this problem. The new VRP variant of Heterogenous Vehicle is used to solve the problems of companies that have vehicles with different capacities in the delivery of their products.

One of the methods that can be applied to solve VRP and its variation is the heuristic method. The heuristic

*Corresponding author: annie.purwani@ie.uad.ac.id 
method is a technique for solving problems with more emphasis on simple computing performance. The heuristic algorithm used in this research is sequential insertion algorithm. Arvianto (2014) explains that the sequential insertion algorithm that has been developed in his model can build a viable solution by repeatedly trying to include customers who have not entered yet to any route should be inserted and the selection of location where the customer is inserted. This algorithm has advantages in the selection of customers, named by considering the customer's position on the available insertion, so the best results can be obtained. This heuristic algorithm is expected to overcome the problems of previous research in the settlement of new variants of the heterogeneous vehicle.

\section{Research Methods}

This study aims to facilitate the decision-making process in determining vehicle routes by considering the type and capacity of different vehicles. The stages of route determination, selection, and scheduling of vehicles consist of preliminary studies and literature, defining problems and objectives, collecting data, processing data, and analyzing the route determination, vehicle selection, and vehicle scheduling

\section{System Characterization}

This study adopts the model of the route and scheduling of vehicles from Arvianto(2014). Products that become the objects of research in PT. Madubaru are packaged sugar consisting of $1 \mathrm{~kg}$ and $0.5 \mathrm{~kg}$. The calculation of the algorithm is done on one of the company's shipment date, August 19, 2016, with 12 customers. Delivery has a planning horizon according to working hours of 8.5 hours by ignoring the rest time. The vehicles used are as follows:

a. Vehicle type L300 capacity $1,500 \mathrm{~kg}$ of 1 unit,

b. Vehicle type PS capacity of $3500 \mathrm{~kg}$ as much as 2 units,

c. Vehicle type $\mathrm{HD}$ capacity of $7,000 \mathrm{~kg}$ as much as 1 unit

The speed of the vehicle used is $50 \mathrm{~km} /$ hour. The loading speed (LT) per minute is 5 sacks and unloading (UT) per minute is 3 sacks. 1 plastic bag containing $25 \mathrm{~kg}$ and loading time (WLT) for each different type of vehicle

\section{Vehicle Routing Model}

The model to be developed in the distribution of packaged sugar has several restrictions as follows:

\subsection{Heterogeneity}

The vehicles used in this research have different types and capacities.

\subsection{Multiple Trips}

One vehicle can serve one or more customers or routes within a single product delivery tour.

\subsection{Split Delivery}

Delivery of products to consumers can be sent directly in one delivery (entirely delivery) or several times the delivery process (partial delivery) based on the condition and the capacity of the remaining vehicles at the time of product delivery

\subsection{Periodic}

Delivery is done by considering the planning horizons that have been determined. If the condition of the cargo on the vehicle has been empty in sending the goods but planning horizon is still there, then the vehicle will return to the warehouse to take the goods and send back to the customer until the planning horizon runs out

\subsection{Stochastic}

The number of subscribers is random or unsystematic. Each customer has the possibility to not be visited every day.

\section{Mathematical Formulations}

According to the distributed characteristics above, a mathematical model will be used as an interpreter of the algorithm to solve the problem. This model adopts from the algorithm which is conducted in the study (Arvianto, 2014):

$i \quad=$ Location index; $\mathrm{I}=0$ is the warehouse, $\mathrm{i}=1,2,3 \ldots, \mathrm{N}$ is the store/retail.

$t \quad=$ Tour index; $t=1,2,3 \ldots, N T$

$r \quad=$ Route index; $r=1,2,3 \ldots, N R_{[t]}$

$k \quad=$ Position index, $\mathrm{k}=1,2,3 \ldots, N L_{[t, r]}$

$z \quad=$ Vechile type index; $z=1,2 \ldots, Z$

$N \quad=$ Number of stores / retail sets $i$

$q_{L t z, r, k}=$ The amount of sugar demand at locations with $r$ routes, $t$ tours and $z$ vehicles ( $\mathrm{kg}$ units)

LT = Loading speed (units: number of products per unit time)

UT = Unloading speed (units: number of products per unit time)

$V_{Z} \quad=$ Speed of vehicle $z$ (unit: distance per unit time)

$\tau_{[L t z, z, r, k],[L t, z, r, k+1]}=$ Travel time of location $k$ to location $\mathrm{k}$ +1 , on route $r$, tour $t$ vehicle $z$ (time unit)

$Q_{z} \quad \quad=$ Capacity on vehicle $z$

$H \quad$ = Horison planning (time unit)

NV $\quad=$ Total number of vehicles (unit units)

NTz $\quad=$ Number of tour vehicles $z$ 


$\begin{array}{ll}N R_{[t, z]} & =\text { Number of routes in tour } t \text { by vehicle } \\ & z \\ N L_{[t, z, r]} & =\text { Number of locations on route } r \text { in tour } \\ & t \text { by vehicle } z \\ & =\text { Location at position } k \text {, route } r \text { in tour } \\ L_{t, z, r, k} & t \text { vehicle } z \\ & =\text { The amount of charge sent on route } r, \\ b_{L t, z, r} & \text { the tour of vehicle } z \\ & =\text { Travel time } \\ W p & =\text { Loading time (time unit) } \\ W L T & =\text { Unloading time (time unit) } \\ W U T & =\text { Tour completion time } t \text { by vehicle } z \\ C T_{[t, z]} & =\text { Total completion tour time (unit } \\ T C T & =\text { Total cost distribution } \\ \text { time) } & =\text { The fixed cost of the vehicle } \\ T C D & =\text { Fuel costs per km } \\ C_{S K} & =\text { Driver's salary visits }\end{array}$

\section{Function Goals}

This research has three objective functions of minimizing as follows:

\subsection{To minimize the number of vehicles (NV)}

In the context of this research problem, by considering the existence of multiple trips, the purpose function is to minimize the number of vehicles $(N V)$. It is because minimizing the number of vessels is the main target model of multiple trips aspects in VRP.

\subsection{To minimize total completion time (TCT)}

This function is required to see the best combination of tours and routes which is generated from the algorithm by considering the work balance represented by the TCT variable

\subsection{To minimize cost distribution (TCD)}

Minimizing total distribution costs $(T C D)$ is a measure of performance as a result of the goal of minimizing $N V$ and TCT.

$$
\begin{aligned}
& \operatorname{Min} \mathrm{TCD}=\sum_{r=1}^{N R} \sum_{i=0}^{N} \sum_{j=1}^{N+1} C_{S K Z} N_{T Z}+C_{G} N_{R}+ \\
& \sum_{r=1}^{N R} \sum_{Z=1}^{Z} C_{B B} V_{Z} W_{P}
\end{aligned}
$$

\subsubsection{Warehouse and Store}

The travel time taken by each vehicle from the starting

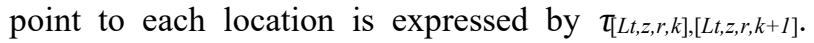
Each customer has a different request that is stated with the $q_{L t z}$ notation. For the notation $L_{t, z, r, 1}$ describes the location of the warehouse where $i=0$ and will end up in the same location, meaning the journey starts from the warehouse and ends in the warehouse.

The location of the warehouse is described as follows:
$L_{t, Z, r, 1}=L_{t, Z, r, N L[t, r]}=0 ; \quad t=1,2, \ldots N T ; \quad z=1,2, \ldots, Z ;$

$r=1,2, \ldots, N R_{[t]}$

The store/retail location is defined as:

$$
\begin{aligned}
& L_{t, z, r, k}=i ; t=1,2, \ldots, N R_{[t]} ; z=1,2, \ldots, Z ; k=2, \\
& N R_{[t, r]}-1 ; i=1,2 \ldots . N
\end{aligned}
$$

\subsubsection{Route and Tour}

Route $r$ is a trip made by one vehicle from a single depot (warehouse) and ends at the same location. The route represents the order of visits of a vehicle to customers, starting from the warehouse and back to the warehouse. A route consists of one depot and at least one customer. The tour is the set of routes that must be passed by vehicle $z$.

\subsubsection{Number of Vehicle}

A number of vehicles denoted by $N V$, for VRP issues with multiple trip characteristics of one vehicle doing one tour. In accordance to the characteristic of the time window, one vehicle may only operate within work hours on a work day determined by the company. This statement is written with the following equation:

Number of vehicle tour type $z=$ number of vehicles

$$
N T_{Z}=N V
$$

The product capacity in vehicle $z$ is expressed by $Q z$ and vehicle speed is $v$. The number of routes in the tour is expressed by the tour $t(t=1, \ldots, N T)$ is $N R_{[t]}$. This type of $z$-vehicle serves multiple routes in a single trip (multiple trips) with a heteroneous fleet so the vehicle begins its journey to route $r$ in the tour $t$ which is the final route location of the previous $r-1$ route in the same $t$ tour.

$$
L_{t, z, r, 1}=L_{t, z, r-1, N L[t, z, r-1]}=0 ; t=1,2, \ldots N T ; z=
$$

$1,2, \ldots, Z ; r=1,2, \ldots, N R_{[t z]}$

A tour consists of a set of routes with $N R_{[t, z]}$ shows the number of routes which is included in a single tour by vehicle $z$. A vehicle route describes the order of vehicle visits to a retail/store which goes and ends to the depot. The split delivery constraint ensures that each subscriber will get at least one delivery so that the demand on location or customer can be delivered with more than one delivery.

$$
\begin{array}{r}
L_{t, z, r, k} \geq 1 ; t=1,2, \ldots N T ; z=1,2, \ldots, r= \\
1,2, \ldots, N R_{[t z]} ; k=2, \ldots N L_{[t, z, r]}-1
\end{array}
$$

The load on each route should be smaller or equal to the capacity of the vehicle. In the case of product delivery, the amount of cargo of each vehicle $z$ which serves a route $r$ in tour $t$ shall not exceed the capacity of the vehicle $z$.

$b_{L, t, z, r,} \leq Q_{z}, \quad \forall t=1,2, \ldots N T ; z=1,2, \ldots, Z ; r=$
$1,2, \ldots N R_{t z} ;$ 
The amount of cargo carried by the vehicle in a tour $t$ by vehicle $z(t, z)$, route $r$ is less or equal to the number of customer requests on route $r$ from tour $(t, z)$.

$$
\begin{array}{r}
b_{L, t, z, r,} \leq \sum_{k=2}^{N L_{[t, r]-1}} q_{L t, z, r, k} ; t=1,2, \ldots N T ; z= \\
1,2, \ldots, Z ; r=1,2, \ldots N R_{[t z]}
\end{array}
$$

Constraint (9) ensures that each subscriber will receive a full demand shipment.

$$
\begin{array}{r}
\sum_{r=1}^{N T} y_{L t, z, r, k}=1 ; t=1,2, \ldots N T ;=1,2, \ldots, z ; r= \\
1,2, \ldots N R_{[t, z]}
\end{array}
$$

\subsubsection{Tour Completion Time}

The completion time of a tour which is expressed by $C T_{[t, z]}$ includes the travel time, and the loading / unloading time available on the tour. The completion time of each tour should not exceed the planning horizon. This tour time is the sum of trip time, loading and unloading time.

$$
\begin{gathered}
C T_{[t]}=(W D T+W U T) \sum_{r=1}^{N R_{[t, z]}} \sum_{i=1}^{n} b_{L_{t, z, r}}+ \\
\sum_{r=1}^{N R_{[t, z]}} \sum_{k=1}^{\left.N L_{[t, z, r]}\right]^{-1}} \tau_{[L[t, z, r, k]],[L[t, z, r, k+1]]}
\end{gathered}
$$

\subsubsection{Travel Time}

Travel time $\tau_{[L t z, z, r, k],[L t, z, r, k+1]}$, is the total time needed by the vehicle $\mathrm{z}$ from the store / retail warehouse up to the warehouse location again. The speed of the ship and the distance between the first location to the second location determine the time of travel.

$$
\mathrm{WP}=\tau_{[L[t, z, r, k]],[L[t, z, r, k+1]]}
$$

\subsubsection{Loading Time}

WLT loading time is the time to load the cargo onto the vehicle $\mathrm{z}$ in the warehouse. The loading time is generated from the amount of packaged sugar which are transported. It means the more cargo to load, the more time needed.

$$
W L T=\frac{b_{[L[t, z, r]]}}{L T}
$$

\subsubsection{Unloading Time}

The unloading time of WUT is the unloading time from the vehicle at the store / retail location. The unloading time of WUT is also obtained from the amount of packed sugar taken out from the vehicle. It means the more cargo to unload, the more time needed.

$$
W U T=\frac{b_{[L[t, z, r]]}}{L T}
$$

\subsubsection{Horizon Planning}

This planning horizon limits the total tour of completion time. The length of the planning horizon is denoted by $\mathrm{H}$. completion time for the $\mathrm{z}$-t ride tour should not exceed the planning horizon.

$$
C T_{[t, z]} \leq \mathrm{H}
$$

\subsubsection{Total Completion Time}

Total Completion Time (TCT) is the sum of all the completion time of all the $t$ tours needed as a solution.

$$
T C T=\sum_{t=1}^{N T} C T_{[t, z]}
$$

The algorithm used to solve the problem in this research is Sequential Insertion Algorithm. Arvianto (2014) explains that this algorithm builds a viable solution by repeatedly trying to include customers who have not entered any route into the temporary portion of the current route. The advantage of the Sequential Insertion Algorithm is trying to generate the smallest possible number of vehicles (tour) by utilizing the capacity of the vehicle as much as possible.

Suprayogi (2005) in his research explains that this algorithm begins by choosing a customer to occupy a position as a seed customer on the first route and tour. In the first customer selection, there are several criteria: earliest deadline, earliest ready time, shortest time window, longest travel time, and random. The criteria for selecting the initial customers (seed customers) included in the next route (second, third, and so on) on a tour that is using completion time of the tour.

\section{Discussion and Conclusion}

The algorithm described previously will be used in the completion of the company's distribution. The selection of stores / retails that deserve to be inserted to the arc insertion is the retails / stores that have the smallest completion time of tour (CT). Calculation will be done for all vehicle types. The optimal decision-making process is done by comparing 3 alternatives for each vehicle type and options of each alternative, which has options and vehicles type combination on the established tour and route.

Comparative analysis results related to the objective functions which are minimizing the number of vehicles used (NV), the total time of completion of the Tour (TCT), and the total cost of distribution (TCD) are presented in the Table 1.

The result of minimizing vehicle is on the third alternative solution with 2 types of vehicle used; those are type HD $(7,000 \mathrm{~kg})$ and type PS $(3,500 \mathrm{~kg})$. Using these vehicles to serve all customers requests of packaged sugar, it needs 2 times of tour with 2 vehicles. This indicates that the more amount of demand, the small capacity vehicles will have many tours and routes which 
lead to the longer total tour completion time and higher distribution cost as well. The shortest total tour completion time is the third alternative solution which results 828.49 minutes.

Table 1 Comparison Results Based on Objective Functions

\begin{tabular}{lccc}
\hline Information & $\begin{array}{c}N V \\
\text { (units) }\end{array}$ & $\begin{array}{c}T C T \\
\text { (minute) }\end{array}$ & $T C D(\mathrm{Rp})$ \\
\hline Exsisting & 4 & 856,70 & $\mathrm{Rp} \mathrm{1.810.826}$ \\
\hline Solution 1 & 2 & 879,97 & $\mathrm{Rp} 1.703 .960$ \\
\hline Solution 2 & 3 & 1053,01 & $\mathrm{Rp} \mathrm{1.370.303}$ \\
\hline Solution 3 & 2 & 828,49 & $\mathrm{Rp} \mathrm{959.011}$ \\
\hline
\end{tabular}

This indicates that TCT is influenced by the duration of tour completion time; the more routes formed in one tour, the longer completion time of the tour will be generated. The duration of the tour completion time is influenced by the vehicle used; the greater of the capacity use, the longer the time will take. The more vehicles to use, the shorter the time will be to serve all customer needs. The impact of the total number of vehicles used is seen on the total cost of packaged sugar distribution. Alternative solution 3 has the least total cost of distribution (TDT) which is IDR 959,011. This shows that if the tours run are fewer, equal to the number of vehicles used (NV), so the total cost of distribution (TDT) will be smaller.

\section{References}

1. Arvianto, A., Setiawan, A.H., Saptadi, S. (2014). Model Vehicle Routing Problem dengan Karakteristik Rute Majemuk, Multiple Time Windows, Multiple Products dan Heterogeneous Fleet untuk Depot Tunggal, Jurnal Teknik Industri, Vol. 16, No. 2, Desember 2014, 85-96.
2. Azizah, U.N., Oesman, T.I. (2015). Optimalisasi Biaya Distribusi Produk PT. Madubaru Dengan Pendekatan Metode Saving Matrix dan Generalized Assignment, Jurnal REKAVASI, Vol. 3, No. 2, Desember 2015, 104-107.

3. Hasanah, Matondang, N., Ishak, A. (2013). Penentuan Rute Distribusi Barang Yang Optimal Dengan Menggunakan Algoritma Heuristik Pada PT. XYZ, eJurnal Teknik Industri FT USU Vol 3, No. 3, Oktober 2013 pp. 48-51.

4. Hermansyah, B. (2011). Penyelesaian Vehicle Routing Problem (VRP) Menggunakan Algoritma Genetika, Skripsi Fakultas Sains Dan Teknologi Universitas Islam Negeri Sultan Syarif Kasim, Riau Pekanbaru.

5. Ikhsan, A.N., Oesman, T.I., Yusuf, M. (2013). Optimalisasi Distribusi Produk Menggunakan Daerah Penghubung Dan Metode Saving Matrix, Jurnal REKAVASI Vol.1 No.1, 1-10, Desember, 2013.

6. Munawir, H., Narima, A. (2012). Penentuan Rute Pendistribsian Kertas Karton Model Studi Kasus: PT. Papertech Indonesia Unit Ii Magelang, Simposium Nasional RAPI XI FT UMS - 2012.

7. Suprayogi dan Imawati, D. (2005). Algoritma Sequential Insertion dengan Forward dan Backward Pass untuk memecahkan Vehicle Routing Problem dengan Multiple Trips dan Time Windows, Jurnal Teknik dan Manajemen Industri, Vol. 25 No. 1, April 2005 